\title{
Holistic View on Electronic Healthcare
}

\author{
Jana Zvárová ${ }^{1}$ \\ ${ }^{1}$ Editor-in-Chief, European Journal for Biomedical Informatics, Prague, The Czech Republic
}

\section{Correspondence to:}

Prof. Jana Zvárová, Ph.D., DSc., Editor-in- Chief,

European Journal for Biomedical Informatics,

Address: Paprsková 15, 14000 Prague, The Czech Republic

E-mail: zvarova@ejbi.org
EJBI 2014; 10(1):1

published: February 28, 2014
Healthcare is an information intensive sector, generating huge volumes of data from hospitals, primary care, clinics, surgeries and laboratories. Information can be extracted from large databases, using nowadays information technologies, and to bring a new knowledge. However, in healthcare sector is working highly educated and knowledgeable personnel, providing the knowledge to processes of medical treatment and healthcare management. The inability to share information across systems and between care organizations is just one of the major obstacles towards quality, efficiency, security and cost-effectiveness of healthcare.

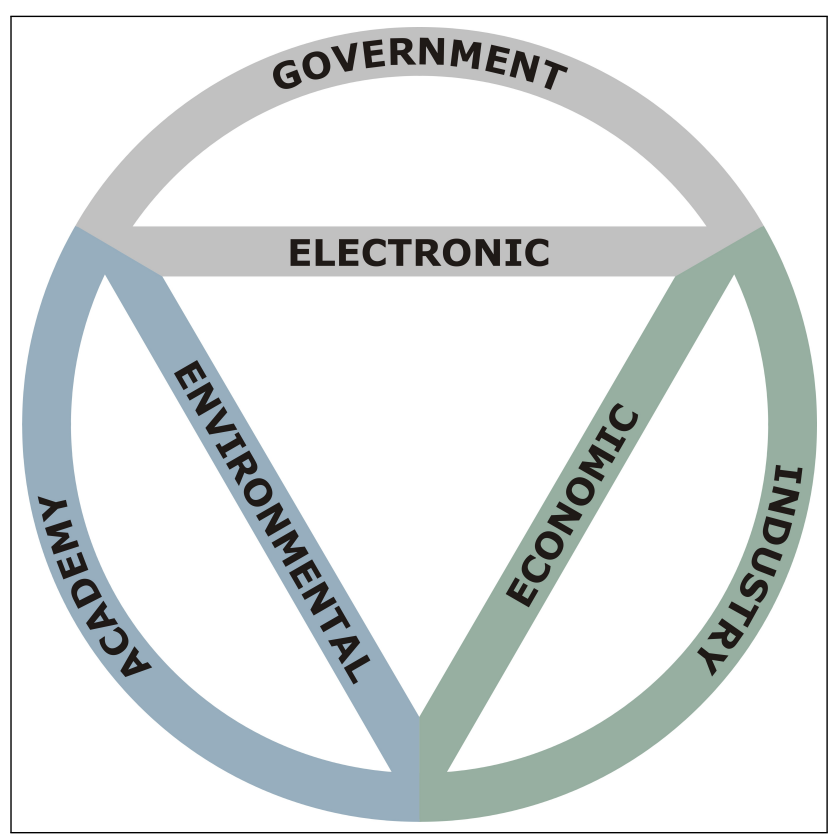

Figure 1: Scheme of holistic electronic healthcare.

There are many reasons for this state, including underinvestment in information technologies, lack of political will, fragmented markets with inadequate development of new systems, lack of standards, complexity of medical data, data entry problems, security and confidentiality. The gap be- tween the demand for healthcare from an increasingly wellinformed citizens and the ability of the government and healthcare organizations to meet this demand is widening all the time.

All these problems in electronic healthcare can be successfully overcome by a holistic approach. Good cooperation among Government, Industry and Academia is a basic prerequisite for building modern healthcare supported by three basic components electronic, economic and environmental [1]. The scheme of holistic electronic healthcare is displayed on Figure 1 .

In the year 2014 European Journal for Biomedical Informatics $(\mathrm{EJBI})$ welcomes original articles dealing with topics influencing electronic healthcare. Authors are not paying an article processing fee for the immediate release of peerreviewed articles, but a small financial support is required in case that the support of projects or sponsors is acknowledged (see Instruction to authors). Due to the focus of the journal to semantic interoperability issues we ask authors for translation of structured abstract of their articles to at least one European language. EJBI provides immediate open access to peer-reviewed papers, which will be published in the running first issue of EJBI during each calendar year. The other issues of EJBI are special issues related to different biomedical informatics topics. Topics for special issues can be proposed to editor-in- chief of EJBI using the form Proposal of EJBI special issue for further processing. Topic for special issue is specified by an open call or by a special event. We invite you to propose special topics that would help to accelerate needed changes in electronic healthcare by easy transfer of a new information and knowledge for health care delivery.

\section{References}

[1] Zvárová J., Zvára K: e3Health: Three Main Features of Modern Healthcare. In: Moumtzoglou A, Kastania A (eds). E-Health Systems Quality and Reliability: Models and Standards, IGI Global Press, New York, 2010; 18-27 